\title{
"Miradas otras": promoviendo prácticas de lectura y escritura desde una cárcel mexicana
}

\section{"Foreign glances": Promoting reading and writing practices from a Mexican prison}

QueTZALli Domínguez SÁNCHEZ*

ÉRIKA RuBÍ SÁNCHEZ SosA*

Mario Miguel OJedA RAMÍREZ ${ }^{* * *}$

Este artículo presenta una intervención para promover la lectura y escritura en personas privadas de la libertad del Centro de Reinserción Social de Pacho Viejo, Veracruz, México. La cartografía lectora consideró el tema del encierro y la paz, cuyos autores publicados estuvieron o siguen en prisión. Durante cuatro meses, las actividades dieron cuenta de las literacidades -desde un enfoque sociocultural-y de las prácticas sociales y culturales situadas. Se obtuvieron 122 bitácoras de los 11 participantes de la intervención. Derivado del análisis, se crearon cinco líneas de interpretación para reflejar las literacidades y los modos de lectura en estas prácticas letradas situadas. Para ilustrar las expresiones, se intercalaron fragmentos de las voces de estas personas sobre sus recepciones de lectura y los distintos significados textuales, emocionales, biográficos, sociales y políticos que generaron. Las múltiples escenas y dimensiones de la lectura contribuyen al conocimiento de las percepciones y reflexiones en espacios penitenciarios. Destaca la importancia de ofrecer una resignificación de la condición de estar privado de la libertad por medio de su escritura y acercar las narrativas creadas en contextos de encierro a la población extramuros a fin de presentar otra perspectiva de la realidad que se vive en prisión.
Palabras clave: lectura y escritura penitenciaria, intervención intramuros, narrativas en contextos de encierro

Recibido: 14 de julio de 2021 | Aceptado para su publicación: 27 de enero de 2022 |

Publicado: 2 de febrero de 2022

Cómo citar: Domínguez Sánchez, Q., Sánchez Sosa, E. R. y Ojeda Ramírez, M. M. (2022). "Miradas otras": promoviendo prácticas de lectura y escritura desde una cárcel mexicana. Sinéctica, Revista Electrónica de Educación, (58), e1357. https://doi.org/10.31391/S2007-7033(2022)0058-005 
An intervention is presented to promote reading and writing with people deprived of liberty from the Pacho Viejo Social Reintegration Center, Veracruz, Mexico. The reading cartography considered the issue of confinement and peace, whose published authors were and/or are still in prison. The activities carried out during four months sought to account for the literacies -from a sociocultural approach-, the situated social and cultural practices. As a result, 122 logs were obtained from the 11 participants of the intervention. Derived from his analysis, five lines of interpretation were created to reflect the literacies and modes of reading in these situated literate practices. To illustrate the expressions, fragments of the voices of these people are interspersed, about their reading receptions and the different textual, emotional, biographical, social, and political meanings. It was shown that there are multiple scenes and dimensions of reading, which contributes to the knowledge of perceptions and reflections in prison spaces. In conclusion, the importance of offering a resignification of the condition of being imprisoned through reading and writing is emphasized, as well as bringing the narratives created in contexts of confinement to the population outside the walls to present another perspective of the reality that lives in prison.
Keywords: penitentiary reading and writing, intramural intervention, narratives in confinement contexts

\footnotetext{
* Licenciada en Lengua y Literatura Hispánicas por la Universidad Veracruzana, México. En proceso de titulación de la Especialización en Promoción de la Lectura de la Universidad Veracruzana. Tallerista intramuros en el Cereso de Pacho Viejo, Veracruz. Coordinadora del colectivo Palabras de Alumbre. Ha colaborado en distintos proyectos con personas en situación de vulnerabilidad (migrantes, trabajadoras sexuales y PPL) a través de sus narrativas, testimonios e historias de vida. Líneas de investigación: lectura y escritura en contextos de encierro. Correo electrónico: zs20000444@ estudiantes.uv.mx/ https://orcid.org/0000-0003-0450-476X

** Licenciada en Sistemas Computacionales Administrativos con especialización en promoción de la lectura. Miembro del Programa Universitario de Formación de Lectores y apoyo académico en la Especialización en Promoción de la Lectura de la Universidad Veracruzana. Líneas de investigación: lectura digital. Correo electrónico: ersanchez@uv.mx/ https://orcid.org/0000-0002-3755-036X

${ }^{* * *}$ Doctor en Ciencias Matemáticas. Decano de la Universidad Veracruzana, miembro numerario de la Academia Mexicana de Ciencias y del Sistema Nacional de Investigadores. Miembro del núcleo académico básico de la Especialización en Promoción de la Lectura y fundador y miembro activo del Programa Universitario de Formación de Lectores de la Universidad Veracruzana. Líneas de investigación: lectura y escritura, metodología de investigación y aplicaciones de la estadística. Correo electrónico: mojeda@uv.mx/https://orcid.org/0000-0001-6161-3968
} 


\section{INTRODUCCIÓN}

er persona privada de la libertad (PPL) en cualquier lugar del mundo signi- fica ser parte de una historia colectiva permeada por el dolor, la violencia y el abandono. Ser PPL en México significa pertenecer a uno de los grupos vulnerados o en posición vulnerable del país, al lado de los migrantes, las víctimas del delito, las mujeres, los niños, las personas que viven en condición de discapacidad como la comunidad sorda, entre otros (Comisión Nacional de los Derechos Humanos, 2010). Morondo (2020) explica que los derechos humanos deberían proteger, en primer lugar, a aquellas personas y grupos cuyos derechos resultan más frecuentemente vulnerados o están más marginalizados respecto a los mecanismos de protección, a quien tiene menos oportunidades y está más oprimido. La vulnerabilidad puede ser vista, entonces, no como una característica de ciertos grupos o sus integrantes o como una condición universal, sino como la condición de indefensión de algunas personas y grupos. Las PPL lo son por muchas razones, que abarcan desde la falta de servicios básicos hasta la de oportunidades para una reinserción social exitosa, como serían las actividades culturales, educativas, laborales y de capacitación (Gómez, 2019).

En consecuencia, no existen mediciones sobre prácticas de lectura e índices de lectores en los centros penitenciarios en México ni tampoco se ha prestado la atención suficiente a las narrativas creadas en contextos de encierro. Cada uno de los 288 centros que hay en el país cuentan con su propia biblioteca; unas más vastas que otras, pero no se sabe si todas tengan sus respectivos bibliotecarios ni las formas en cómo operan dentro de esos espacios. Para Frugoni (2018), son muchas las experiencias que muestran que las bibliotecas en estos lugares pueden ser espacios poderosos de encuentro, circulación de palabras silenciadas y cruce de experiencias y saberes. En las cárceles mexicanas no hay un programa nacional especializado en la formación de lectores PPL, pero sí existen espacios (Armijo, 2018; Chávez, 2020; Documentación y Estudios de Mujeres, AC, 2020; Estrada, 2016; Frías, 2019; Reinserta, 2020), que están dedicados a fomentar este tipo de prácticas y a obtener producciones plasmadas en libros, revistas, páginas web. Están también los enfocados al aspecto educativo en aulas (Gutiérrez, Hidalgo \& Espinosa, 2018; Morales, 2017; Ortiz, 2014).

Con los ejemplos anteriores, entendemos que las prácticas dedicadas a lo artístico y educativo en estos contextos provienen de intervenciones de universidades o proyectos autogestionados por las mismas PPL, estudiantes, bibliotecas o colectivos que conquistan un lugar propio a fuerza de perseverancia y negociación con el servicio penitenciario (Frugoni, 2020).

Investigadores que trabajan en estos espacios (Díaz y Mora, 2018; Gómez, 2017; Parchuc, 2020) están de acuerdo en que este tipo de talleres penitenciarios son urgentes y necesarios: poderosas poleas de transmisión para nuevos vínculos de espaldas a la deshumanización promovida por las lógicas carcelarias (Frugoni, 2020). También hay estudios en otros países dedicados al tema (Sequeiros, 2018; Temple, 2018) que, desde sus intervenciones, presentan metodologías de cómo trabajar la lectura en cárceles. Este tipo de formaciones comprometen al sujeto a la reflexión de sí mismo, de quién es y de aquello que sabe, y lo involucra en un espacio compartido (Bustelo, 2017), que genera saberes personales y colectivos, apropiaciones de lecturas, prácticas autorreflexivas 
escriturales, "prácticas transformadoras y complejas que permiten explorar y fortalecer las condiciones de autodescubrimiento, además de reconocer multiplicidades de escenas, tiempos y localizaciones del poder" (Sánchez, 2021, p. 7).

El taller de escritura creativa "Palabras de alumbre" ha sido un espacio creado en febrero de 2020 dentro del Centro de Reinserción Social (Cereso) de Pacho Viejo en el estado de Veracruz. Este lugar desafía las formas tradicionales de la enseñanza pedagógica y producción de textos, al articular ejercicios y prácticas escriturales emancipatorias en las que los participantes innovan y proponen. Este proyecto, que nació desde lo empírico, el gusto y placer por la lectura y un tanto, habrá que decirlo, de la improvisación y lo pragmático, fue luego enmarcado en un ámbito académico profesionalizante. Con ello se fundamentó y articuló un modelo metodológico que previó la evaluación y el reporte de resultados.

Por ello, ha sido importante prestar atención especial a las experiencias personales, percepciones y reflexiones de los participantes de las actividades de esta intervención. Según Bustelo (2017), estas se diluyen de las categorías tradicionales de educación formal y no formal, ya que suponen ser construcciones en sí mismas transformadoras, pero, a su vez, comprometen a la persona en un espacio de construcción colectiva, porque se trabaja con lecturas y ejercicios estimuladores para la escritura; se intercambian los textos entre ellos y sus familiares de afuera, se forman cartografías lectoras y se invita a participar a personas que permanecen extramuros.

\section{MARCo CONTEXTUAL}

Goffman (2001) define a las instituciones totales como "un lugar de residencia y trabajo, donde un gran número de individuos en igual situación, aislados de la sociedad por un período apreciable de tiempo, comparten en su encierro una rutina diaria, administrada formalmente" (p. 13) y las cárceles son un ejemplo notorio. Las características centrales de las instituciones totales son las siguientes: todos los aspectos de la vida se desarrollan en el mismo lugar y bajo la misma autoridad única; cada etapa de la actividad diaria del miembro se lleva a cabo en la compañía inmediata de un gran número de otros, a quienes se da el mismo trato y de quienes se requiere que hagan juntos las mismas cosas; todas las etapas de las actividades diarias están estrictamente programadas mediante un sistema de normas formales explícitas y un cuerpo de funcionarios; y, finalmente, las diversas actividades obligatorias se integran en un solo plan racional deliberadamente concebido para el logro de los objetivos propios de la institución.

Las instituciones totales son manejadas por organizaciones burocráticas y están orientadas a la vigilancia. Existe un gran grupo manejado en forma adecuada llamado "internos" y un pequeño grupo "personal supervisor". Los internos viven dentro de la institución y tienen limitados contactos con el mundo, y los supervisores, lo contrario.

La literacidad se concibe como la lectura y escritura vista desde el enfoque sociocultural que involucra valores, actitudes, sentimientos y relaciones sociales que estimulan procesos internos del individuo (Cassany y Castellà, 2010; Zavala, 2008). En este sentido, Orozco y Pérez (2021) mencionan que la literacidad deriva de la lectura y escritura creadas en distintas realidades sociales, históricas y 
culturales. Su estudio permite entender el uso determinado del lenguaje dentro de una sociedad. Para ello, es indispensable identificarse como miembro de un grupo social, en este caso las PPL. A partir de estos grupos, podemos estudiar cómo funciona su lectura y escritura, así como la creación de narrativas que exponen injustica, explotación o violencia.

Bustelo (2017) se ha acercado a las narrativas en contextos de encierro producidas en la cárcel, lugar que despersonaliza, promueve almas solitarias y estrategias de supervivencia individual. Escribir en la cárcel puede ser una herramienta literaria que interpela críticamente a la sociedad, una oportunidad de revisar los propios esquemas y clasificaciones (Parchuc, 2014, 2020). Por ello, estas escrituras son tan poco vinculadas a la sociedad civil. Frugoni (2020), por su parte, piensa que esta desvinculación se debe a que la lectura y escritura dentro de la cárcel dignifica las vidas de las PPL, rompen el aislamiento y tienen el potencial de denunciar las violencias y los silencios; también se pueden tener redescubrimientos, diálogos inconclusos, que recaen muchas veces en ajustes de cuentas consigo mismos, reconocimientos de sus actos, asumir sus vidas en torno a las prácticas lectoras y los personajes de las lecturas leídas.

\section{OBJETIVO}

La intervención, en modalidad de actividades asíncronas, impulsó la formación de lectores y escritores en el Cereso de Pacho Viejo, Veracruz, que compartieron reflexiones críticas, escritos y propuestas a partir de una cartografía lectora llamada "Sobre el encierro y la paz", conformada con textos de literatura y periodismo, divididos en dos bloques de lecturas. Procuramos leer publicaciones de escritores presos para visibilizar las narrativas creadas en ese contexto. Asimismo, dar a conocer una mirada empática sobre la condición de ser PPL y contribuir al cambio de discursos de ciertos imaginarios sociales punitivos relacionados con el sufrimiento obligatorio de las personas en un ambiente violento y anómico (Vilchez, 2020).

\section{Metodología}

La intervención se realizó siguiendo la metodología de investigación-acción. El modelo metodológico se centra en llevar a cabo una acción o intervención dentro de una comunidad para atender un problema y ocasionar una mejora. Como característica resalta la aplicación en un terreno práctico. Busca analizar la práctica del investigador y la comunidad, y es primordial la reflexión de ambos (Botella y Ramos, 2019). Las actividades, así como la estrategia implementada, buscaron dar cuenta de las literacidades -desde un enfoque sociocultural-, las prácticas sociales y culturales situadas. En consonancia con el énfasis cualitativo, llevamos a cabo un análisis del discurso, introspección, así como la lectura y escritura crítica (Fairclough, 2008; Federighi, 2019; Kumar, 2018); es decir, consideramos la variedad de interpretaciones de un texto evaluando sus efectos en el grupo (Cassany y Castellà, 2010).

Como lo indica la investigación-acción, el promotor se acercó a los participantes para conocer cualitativamente qué hacen con los textos y los significados formados alrededor de las prácticas letradas que reflejan identidades e interpretaciones del 
mundo (Zavala, 2008), y estimulan la empatía y la autorreflexión. Buscamos mostrar puntos en común ante la recepción de las infinitas escenas derivadas de la lectura (Bombini, 2008) y la escritura de narrativas en contextos de encierro.

\section{Estrategia de intervención}

La intervención estuvo enmarcada en las actividades académicas de la Especialización en Promoción de la Lectura de la Universidad Veracruzana durante la emergencia sanitaria provocada por la COVID-19, de noviembre de 2020 a marzo de 2021. Cada semana entregamos a la dirección del área educativa del penal un portafolio para cada alumno con lo siguiente: una lectura de la cartografía lectora; los ejercicios de creación revisados con correcciones ortográficas y notas; una guía (en forma de correspondencia) que explica el trabajo a realizar esa semana; una memoria USB con videos asíncronos sobre la clase y material audiovisual acerca del tema en cuestión (entrevistas a los autores leídos, material informativo sobre el tema a abordar). Por semana y por cada lectura leída, los participantes enviaron una bitácora como forma de reportar su recepción de la lectura y el ejercicio de creación que indicó la mediadora. Realizamos una entrevista final a cada uno de ellos por medio de videollamada, mediante la cual recolectamos los datos necesarios para reportar los resultados de esta investigación.

Todas las actividades fueron escritas y abrieron una brecha hacia la libertad de la escritura. Invitamos a no repetir discursos de los que, según Vilchez (2020), "se espera de un preso en 'resocialización' que tiene que demostrar la efectividad del 'tratamiento penitenciario'” (p. 185). De esta forma, observamos, desde diferentes perspectivas, miradas, voces y experiencias, la realidad carcelaria y social mexicana, así como la oportunidad de ofrecer una resignificación sobre las PPL. Para motivar la expresión de los participantes, utilizamos la cartografía mostrada en la tabla 1.

Tabla 1. Cartografía lectora

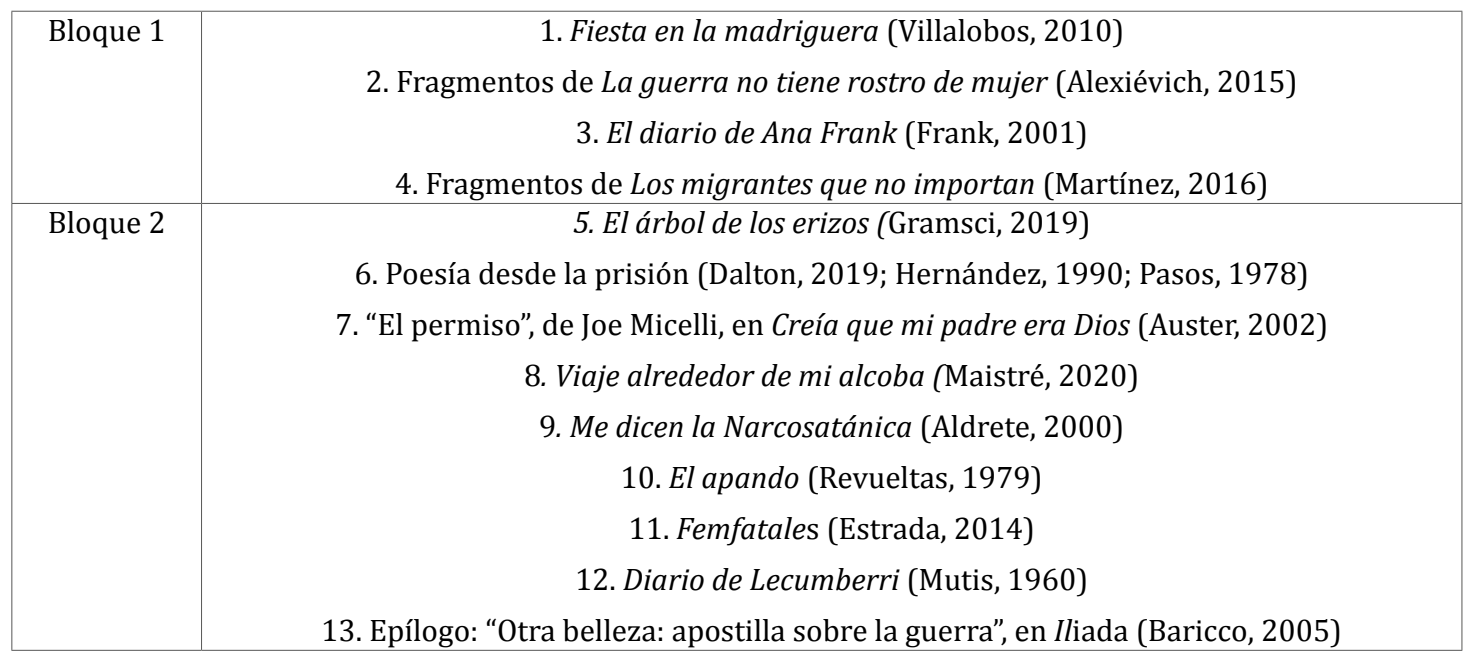

La mediadora, que funge como la primera autora de este escrito, observó y tuvo en consideración la figura del otro como un semejante. Se concientizó que este 
era un trabajo realizado con personas con trayectorias vitales marcadas por la exclusión social, el sufrimiento, la degradación (Acin, 2016), como son las PPL, y con las dimensiones emocionales de la lectura (Morales, 2019) que se posibilitan entre ellos. Partimos del supuesto de que la propia experiencia de lectura literaria gatilla múltiples posibilidades de significación (Sánchez y Druker, 2021). Entendimos también que la cárcel es un entorno que incluye no solo a los presos, y el afuera y adentro no son espacios sin conexión (Vilchez, 2020).

\section{Participantes}

El grupo de intervención en cuestión estuvo compuesto por 11 PPL ( 9 hombres y 2 mujeres) de entre 35 y 69 años, que representaron el 1.3\% de la población total del penal que, al momento de la intervención, albergaba aproximadamente a 969 PPL. Las características del grupo se presentan en la tabla 2.

Tabla 2. Composición del grupo

\begin{tabular}{|c|c|c|c|c|}
\hline Participantes & Sexo & Edad & Estudios universitarios & Estudios de posgrado \\
\hline 1. A.B. & $\mathrm{M}$ & 39 & No & No \\
\hline 2. C.E. & $\mathrm{M}$ & 43 & No & No \\
\hline 3. C.A. & $\mathrm{M}$ & 39 & Sí & No \\
\hline 4. E.G. & $\mathrm{M}$ & 45 & Sí & Inconclusos \\
\hline 5. F.G. & $\mathrm{M}$ & 51 & Sí & So \\
\hline 6. F. del. C. & $\mathrm{F}$ & 37 & Estudiante & Sí \\
\hline 7. J.M. & $\mathrm{M}$ & 36 & Sí & No \\
\hline 8. J.P. & $\mathrm{M}$ & 37 & Sí & No \\
\hline 9. J.L. & $\mathrm{M}$ & 69 & Sí & Sí \\
\hline 10. L.H. & $\mathrm{M}$ & 35 & Estudiante & \\
\hline 11. Y.G. & $\mathrm{F}$ & 53 & Sí & \\
\hline
\end{tabular}

Vale la pena reflexionar sobre estos sujetos lectores. De acuerdo con el último Censo Nacional de Gobierno, Seguridad Pública y Sistema Penitenciario Estatales, en el módulo 3 sobre Sistema Penitenciario del Instituto Nacional de Estadística y Geografía (INEGI, 2020), hay 288 centros penitenciarios en México, con un total de 181,534 PPL. De esta población, el 37.6\% de los internos tienen únicamente estudios de secundaria; el 32.5\%, el preescolar o la primaria; el 13.9\%, la preparatoria; solo un 3.7\%, la licenciatura; el 0.1\%, una maestría; y el 0.4\%, un doctorado.

Con estos datos a priori, observamos que en el grupo de intervención el $72 \%$ son hombres, el $80 \%$ tienen estudios universitarios terminados o están estudiando, y el 36\% cuentan con estudios de posgrado terminados o inconclusos. Por ello, podemos concluir que quienes participan en este espacio son, en su mayoría, personas con un grado académico que buscan estas oportunidades para seguir aprendiendo. Los datos proporcionados por el INEGI no se corresponden con la realidad de los lectores del taller, lo cual volvió la intervención un ejercicio mucho más interesante. A continuación, la gráfica 1 muestra información sobre el estado inicial del grupo. 
Gráfica 1. Hábito de lectura y escritura antes del taller penitenciario

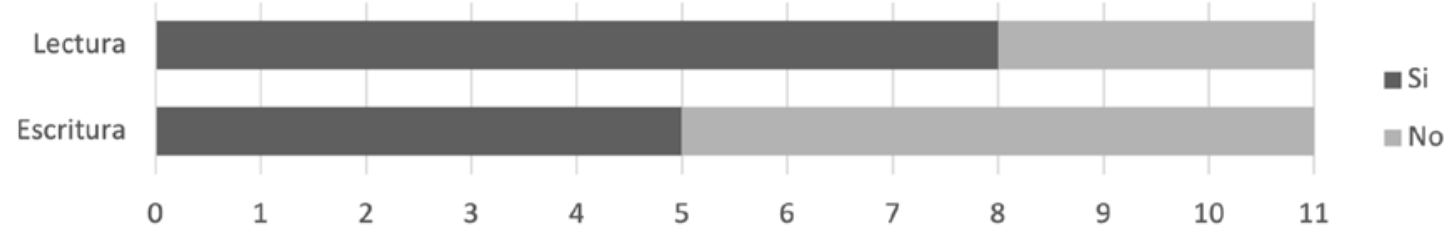

De los 11 participantes, ocho de ellos ya eran lectores previos, lo que demuestra que forman parte del sector con adquisición de capital cultural legítimo (Bourdieu, 1997), que tuvieron educación universitaria y que la lectura estuvo al alcance de ellos, desde niños o jóvenes. Así también, cinco participantes ya practicaban la escritura creativa desde antes, pero sin pretensiones de publicar o profesionalizarse en el tema.

\section{Instrumento de análisis}

De acuerdo con la investigación-acción, hay que acercarse a la problemática de la comunidad. En este caso no basta solo observar las prácticas de lectura y escritura, sino que se vuelve importante aproximarse también a las prácticas sociales que se tejen a su alrededor y que van construyendo el valor del texto (Zavala, 2008). Los instrumentos de análisis de la intervención fueron dos: las 122 bitácoras de las experiencias de lectura de la cartografía lectora hecha por los participantes; y las líneas de interpretación que se encontraron en las bitácoras. A partir de estas narraciones escritas, efectuamos un análisis cualitativo para develar las relaciones sociales en el contexto carcelario (Kumar, 2018), así como las literacidades.

\section{RESULTADOS Y DISCUSIONES}

Los resultados destacan el aspecto cualitativo. Sánchez y Druker (2021) mencionan que la experiencia propia de la lectura literaria gatilla múltiples posibilidades de significados, los cuales pueden ser textuales, emocionales, biográficos, sociales y políticos. La significación se da a través de las historias personales, y no es posible disociar estas posibilidades. Se da pauta a conocer las prácticas lectoras situadas (Cassany y Castellà, 2010), las literacidades socioculturales, y las interpretaciones del mundo que hace el lector (Bombini, 2008) a través de una cartografía propuesta, que invitó a una reflexión crítica, en la que se puede leer lo que las infinitas escenas derivadas de la lectura propician.

\section{Resultados}

Al realizar el análisis de las literacidades de 11 PPL, comprobamos la significación personal otorgada a cada lectura. En las bitácoras elaboradas por cada participante se plasmó sobre todo cómo ven el proceso de reclusión y búsqueda en la que cada uno se encuentra, los niveles de socialización de las lecturas, cómo se presentan ante su escritura propia, la relación que establecen individualmente con la lectura y las reflexiones sobre la cartografía. Esto lo expondremos a continuación en cinco líneas de interpretación. 
Línea de interpretación uno: entender la reclusión desde adentro y el reconocimiento de sí mismos

En las lecturas realizadas y sus correspondientes bitácoras, los participantes recalcan que no es posible entender la cárcel si no se ha estado dentro de ella. Bustelo (2017) señala que "la cárcel es hablada con la soltura que solo el conocimiento de quien estuvo adentro puede mostrar. Esa experiencia localizada, singular, sensible, es parte de su historia, y ellos tienen herramientas para contarla. Conocen la cárcel, la recorrieron, saben sus vericuetos, sus huecos y su superficie. Conocen sus gentes, sus habitantes, sus puntos de fuga" (p. 55). Esta afirmación se aprecia en la opinión del participante J.M. tras la lectura de El diario de Ana Frank: "Gracias por la lectura, la primera vez que leí este libro no podía atisbar ni remotamente el aspecto emocional que ostenta un libro que habla de lo que hoy vivo en prisión" (comunicación personal, noviembre de 2020).

A su vez, se percibe cómo los participantes se reconocen a sí mismos y en colectivo a través de su escritura, como lo refleja el siguiente fragmento de la bitácora final:

Este taller-cofradía me da armas para quitarme la etiqueta que quieren imponerme y tirárselas al suelo. [...]. Somos los 12 apóstoles de nuestro evangelio propio. [...]. Somos palumbreros cautivos donde nuestras cicatrices gritan, rugen en nuestros escritos. Estamos inconformes, con las lecturas tomamos convicción de nuestra inconformidad, porque esta cartografía inseminó rebeldía, dignidad. Con ella imaginamos, soñamos, añoramos y extrañamos. Nos convertimos en escritores en potencia (E.G., comunicación personal, marzo de 2021).

También tenemos el siguiente ejemplo en la bitácora de la lectura Viaje alrededor de mi alcoba:

¡Sin mentir afirmo! Yo, C.A. en pleno uso de mis facultades mentales, confirmo que soy mucho más libre dentro del Cereso de Pacho Viejo Veracruz, que estando no preso deambulando por las calles de mi amada ciudad. [...]. Afuera era un ciego en tierra de ciegos, aquí dentro soy un tuerto en tierra de personas (tribu) negadas a ver. ¡No me mal interpreten! ¡No soy feliz! Trato de serlo ¡Pero estoy incompleto! ¡Nunca podré sustituir lo que me falta! ¡No existe con qué! si tengo sed, por comer arroz, no quedaré saciado. ¡Necesito agua! Y aquí adentro ¡no-existe-mi-líquido-vital! ¡Está afuera! Yo solo estoy tratando de llegar a ella (C.A., comunicación personal, enero de 2021).

Estas afirmaciones muestran autorreflexión y parte de la interpretación de su mundo como PPL de manera individual y colectiva, como mencionan Cassany y Castellà (2010) y Zavala (2008). Mostrar estos fragmentos sirve como ejemplo de la creación de nuevos vínculos identitarios de espaldas a la deshumanización carcelaria de la que habla Frugoni (2020).

Línea de interpretación dos: textos libres, papel reciclado o piñatas: cómo se mueve la lectura dentro y fuera de una cárcel

Conocer el destino de los textos enviados semana tras semana en su carpeta nos permitió analizar de qué manera se mueve la lectura en un espacio penitenciario, donde se vive un ritmo de vida completa y absolutamente desligada de la dimensión del tiempo social-comunitario-global del afuera. Las respuestas fueron reveladoras para fines de este texto. 
El 72.7\% del grupo, es decir, ocho participantes dijeron sí haber guardado las 13 lecturas enviadas. Tres de ellos hicieron llegar las que les parecieron acordes con sus hijos o sobrinos, como el libro-álbum El árbol de los erizos. Una de las respuestas más interesantes fue la de F.G., quien, al preguntarle si guardaba las lecturas en algún lugar particular, respondió: “... a modo de experimento, a veces dejo las copias sobre la mesa del comedor, y me entra un sentimiento como de agradecimiento cuando veo a los compañeros que se acercan (que no están en el taller) y lo respetan. Que sí los leen, no los tiran, no los maltratan, y los vuelven a dejar ahí. Ciertamente no atesoro las lecturas, sino que las trato de compartir" (comunicación personal, abril de 2021).

El 27.3\%, es decir, los tres participantes restantes, no guardaron los textos; A.B. respondió que utilizó el papel como material reciclado para hacer una piñata:

Híjole, la verdad, ya cuando vi que tenía muchas hojas, hice una piñata. Pero también le doy las lecturas que nos mandas a mis tres compañeros de celda, más cuando no hay tele, me dicen "a ver pásame otro de tus folletos", y sí se ponen a leer. Entonces de todos lo que nos mandas, escojo los mejores según mi gusto y los comparto, y ya los otros los separo para piñatas (comunicación personal, abril de 2021).

Este comentario es revelador para entender cómo es que a los textos (cualquier que sea) también se le puede llamar simplemente "folletos". Es necesario aceptar la realidad de que las personas algunas veces se acercan a la lectura por aburrimiento o por la imposibilidad de hacer otra cosa más en ese momento. Como menciona Argüelles (2020), para formar lectores hay que dejar atrás los estereotipos sobre la lectura y sus lectores. En conclusión, la mayoría de los participantes dijeron haber hecho que estos 13 textos transitaran de mano en mano, así fuera entre compañeros internos o fuera del penal para sus familias. Esto es un logro que cumplió con una función socializadora, objetivo que resultaría beneficioso implementar, en mayor medida, para crear sinergias entre las PPL y sus relaciones interpersonales de dentro y fuera a través de la lectura.

Línea de interpretación tres: arrastrar el lápiz... Otras escrituras no literarias: ¿qué escriben las PPL en su vida cotidiana?

Haciendo caso de las propuestas de Zavala (2008) para los usos de la lectura y la escritura, se retoma que, más allá de la escuela, no son fines en sí mismos: uno no lee o escribe para leer y escribir, sino, al contrario, "son formas de lograr objetivos sociales y prácticas culturales más amplios" (p. 24). Como afirman Cassany y Castellà (2010), la propuesta sociocultural otorga mucho valor a las denominadas "prácticas letradas vernáculas" o autogeneradas, es decir, a las formas de lectura y escritura que desarrolla por su cuenta el aprendiz en contextos privados. Una primera literacidad vernácula en el Cereso podría pensarse en "Lápiz de protesta" y "Sin censura", pequeños espacios dentro del periódico mural del penal, en los que las PPL pueden "mostrar" sus inquietudes, molestias, literatura, discursos en contra de las instituciones, etcétera; es un lugar de demanda social que las PPL protegen, escriben y leen. En la gráfica 2 observamos lo que los participantes comparten respecto a sus escrituras cotidianas dentro del penal. 
Gráfica 2. Escrituras no creativas. ¿Para qué utilizan la escritura los participantes en su vida cotidiana?

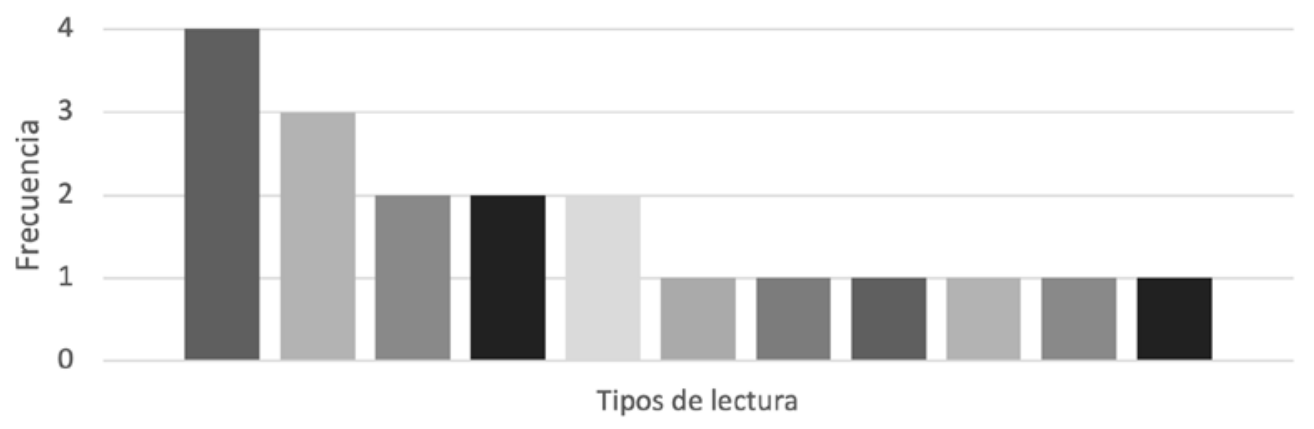

$\begin{array}{lll}\text { Notas } & \text { Dibujar o diseñar } & \text { Cuentas } \\ \square \text { Listas } & \text { Cartas } & \text { Mandalas } \\ \text { Decretos } & \text { Caligrafía } & \text { Escribir sueños } \\ \text { Números en el pizarrón } & \mathbf{a} \text { Tareas } & \end{array}$

La gráfica 2 demuestra que todos ellos tienen o crearon sus literacidades vernáculas, ya que cuatro escriben notas, tres utilizan la escritura para diseñar o pintar, hacer cuentas, listas, cartas, decretos, etcétera, y estas son creaciones personales no impuestas por las instituciones, lo cual vuelve interesante comprender que estos lectores ya tenían un acercamiento a lo letrado, sin saberlo quizá, pero llegaron a estos espacios de escritura. No obstante, según sus respuestas, ellos no creían que escribir algo no relacionado con escribir literatura fuera escribir.

Zavala (2008) señala que no se puede decir que la lectura y la escritura solo yacen sobre el papel. Como el uso de la literacidad es esencialmente social; no se localiza solo en la mente de las personas o en los textos leídos o escritos, sino también en la interacción interpersonal y en lo que la gente hace con estos textos. Es interesante la respuesta de J.P. sobre este tema: "El lápiz y la libreta son una herramienta importantísima de chamba para mí porque soy corredor de comida del restaurantito que hay aquí. Diariamente levanto pedidos con los compas de todo el penal y anoto todas mis listas y cuentas" (comunicación personal, abril de 2021), y la de J.M.: "Todos los días (en mi vida extramuros todos los días tenía que escribir por lo menos notas médicas y eso es una aplicación práctica, al igual que hacer reportes del estado de salud de los pacientes, a veces tienes que ser el narrador de la historia de los enfermos), aquí también hago notas médicas" (comunicación personal, abril de 2021).

Por su parte, C.E. dice que utiliza la escritura "para trazar y diseñar mis artesanías. Hago mis propios diseños, originales" (comunicación personal, abril de 2021) o E.G.:

A mi mujer le gusta que le escriba cartas, eso hago periódicamente; también a mis hijas, como lo hace Gramsci. También dibujo bastante, el trabajo de artesanías requiere mucho dibujar; practico caligrafía también porque en las artesanías luego se ponen nombres y dedicatorias, para eso lo hago; y en mi trabajo como maestro aquí en el Cereso escribo en el pizarrón, pero números, matemática y física (comunicación personal, abril de 2021).

Con esto, sabemos que al menos cuatro participantes utilizan la escritura en su práctica laboral, pero también como forma de relacionarse con los otros. Estas respuestas 
son claro ejemplo de que, si situamos la lectura y la escritura en contextos y motivaciones de uso más amplios (como leer una receta de cocina para aprender a cocinar) o como este ejemplo de anotar todo el tiempo cuentas y listas, entonces podemos afirmar, de acuerdo con Zavala (2008), que los textos que leemos y escribimos se insertan en las prácticas de nuestra vida y no al revés.

Línea de interpretación cuatro: resonancias, espejos y puentes con la lectura

Sin duda, este apartado es uno de los más importantes, ya que muestra de manera clara que la apropiación de una misma lectura no es igual para todos los participantes de un conglomerado que forma parte de un taller de lectura. A pesar de que el texto que tuvo más resonancias en los participantes fue el libroálbum El árbol de los erizos, advertimos que no tuvo una diferencia significativa de menciones, sino que de los 11 participantes se eligieron textos diferentes, y se tuvo en segundo lugar como lecturas-espejos El Diario de Ana Frank y Fiesta en la madriguera.

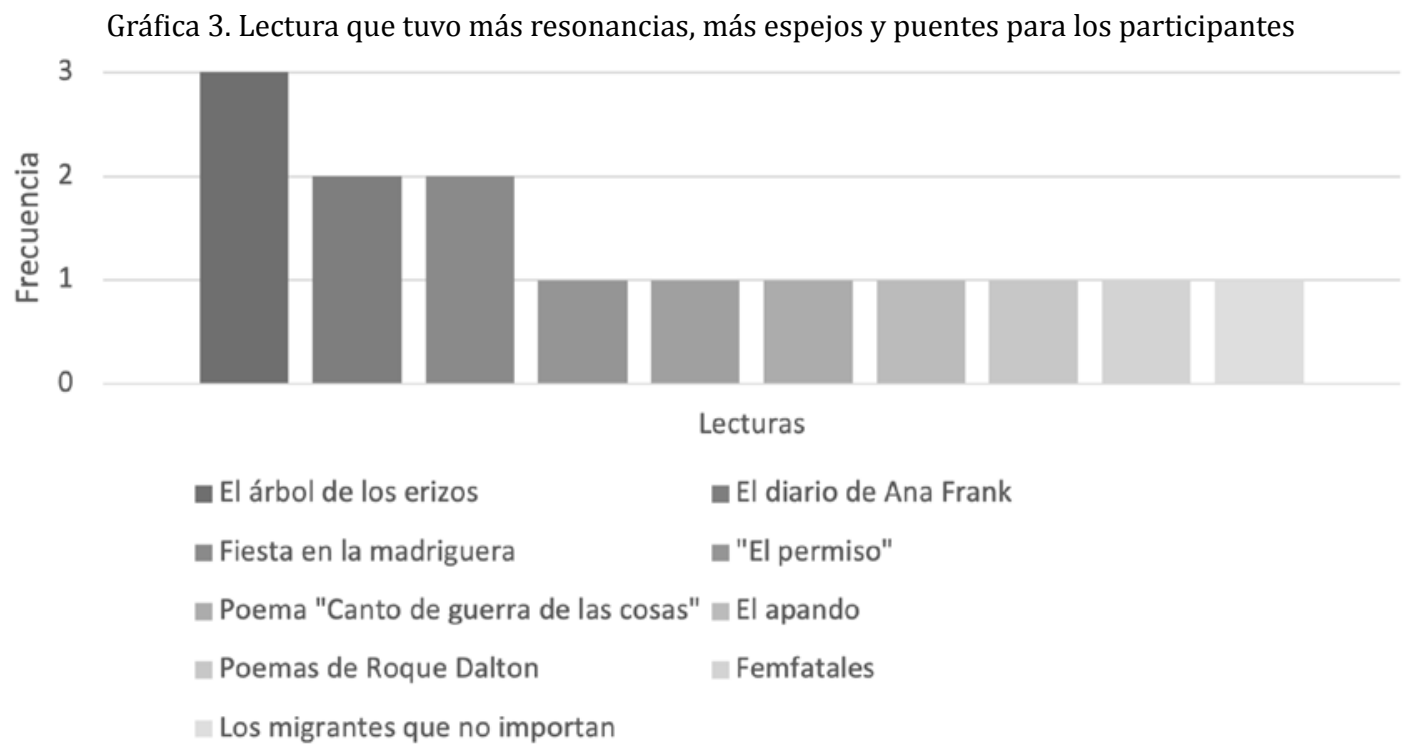

Aquí vale la pena dejar a la reflexión cómo es que se encuentran diferencias entre lo que es una lectura favorita y aquella con la que se tiene más resonancias o espejos; comprender que hay distintas recepciones en un mismo lector, parámetros propios de lo que es una lectura significativa por una dimensión u otra/ otras, ya que no todas tocan los mismos puntos ni todas hacen encontrar los mismos significados de los que hablan Sánchez y Druker (2021). Así también, comprender que como promotor a veces se cree que una lectura específica será la más importante o significativa en un ejercicio de intervención y en los resultados se arroja lo contrario, lo cual es natural, y hay que aprender a no crear expectativas lectoras focalizadas en que se lea de la misma forma un texto, al poder ser imparcial y global. 
Línea de interpretación cinco: ¿qué es el encierro y qué abarca? Reflexiones en torno al tema de la cartografía

En la entrevista también pudimos dialogar sobre lo que para ellos (tras el acompañamiento de las 13 lecturas de la cartografía) era ahora el encierro, cómo lo redefinían, si había cambiado su visión sobre el tema, y si existían distintos tipos de encierro, o no. J.P. afirma:

Aquí adentro he ampliado mi visión de la libertad, aquí adentro se puede ser preso o se puede ser libre. Y también se aprende a valorar las prácticas y posibilidades que afuera de la cárcel se tenían, pero no se desarrollaban, y ahora acá se tienen necesidades apremiantes por recuperar recursos internos, personales, herramientas que dan sentido y libertad y una vivencia más plena a la cárcel. Así que, por supuesto que las lecturas que he hecho han cambiado mi noción de libertad y de encierro, y mi forma de vivirla (comunicación personal, abril de 2021).

Por su parte, C.E. comenta:

Es una pregunta muy fuerte. Yo llevo 17 años aquí encerrado y tal vez ahorita me cueste leer lo que tú me traes porque después de 17 años aquí, haces una vida y aprendes a vivir aquí; creas vínculos con personas, haces amistades, yo aquí tengo una pareja, y aprendes a vivir esta situación, pero no te acostumbras, porque nunca te acostumbras. La libertad es la libertad, pero hay encierros más grandes, la última carta que te mandé te dije que yo tuve un encierro dentro de la cárcel y dentro de mí mismo, del cual pude salir y como te dije, no he creado mis alas porque no he podido, pero esas me las voy a construir cuando salga. Pero a mí ya el encierro (no te digo que no me afecta porque le hago falta a los míos y me hacen falta a mí) pero ya salimos de este trauma, mi hijo, mi familia y yo, que vivimos en un principio; lo hemos ido trabajando por años, y años y años. Hoy ya tengo más comunicación con todos ellos; mi hijo ya es un hombre, acaba de cumplir 18 años. Y todo esto me satisface, me hace sentir más libre y con menos carga. Ahorita me faltan 4 años para que me vaya yo, y ya estoy esperando solo eso para enfrentarme a la libertad, ahora sí ya enfrenté al monstruo de la cárcel, ahora me tengo que enfrentar al monstruo de la libertad, el de la sociedad, a enfrentar a todos los que van a saber que vengo saliendo de este encierro, con la etiqueta que me pusieron (comunicación personal, abril de 2021).

Otra respuesta interesante fue la de J.M.:

Pues creo que ya para los casi cinco años que llevo preso estoy mimetizado con este ambiente. He tenido un proceso psicológico, físico [...] si esta pregunta me la hubieras formulado en los meses o días previos a mi encarcelación la respuesta hubiera sido francamente diferente. Para estas alturas, no me parece nada raro lo que expresan los autores, es una cotidianeidad [sic], ya no es novedoso. Ya para el tiempo que llevo aquí, tampoco es que lleve siglos, pero yo también ya tuve contacto con toda esta realidad; para mí lo diferente sería lo opuesto. ¿Cómo es ahorita la vida extramuros? No la logro determinar a conciencia plena. Actualmente, si yo leo una novela contemporánea, me parece algo desconocido, interesante, hasta apasionante. Pero leer a gente que ha pasado por el encarcelamiento, me parece algo común, e inclusive, incompleto, porque las cárceles mexicanas son algo terrible y aún ficcionalizando siempre se ha quedado corto, son esbozos. No se ha llegado a ese grado máximo de hiperrealismo (comunicación personal, abril de 2021).

Por último, la mirada de una de las chicas: Y.G.:

Identifiqué que sí hay distintos tipos de encierro, incluso no es necesario estar en la cárcel para vivirlo. Pero ¿qué es? No sé si podría definir todo lo que para mí implica y todo lo que sus brazos llegan a tocar. Lo sufrimos muchos, no solo los PPL, afecta a todo nuestro entorno. Abarca todo lo que nos importa y a todos los que queremos. Es tristeza, asfixia, enojo, impotencia, miedo (comunicación personal, abril de 2021). 
Una vez mencionadas las cinco líneas de interpretación, presentamos la tabla 3 con las dimensiones críticas encontradas en las literacidades de los participantes. Para el análisis crítico del discurso (ACD), destacamos la relación entre texto, discurso, aspectos sociales y significación. Tomamos como base las bitácoras producidas por los participantes. En estos textos se plasmaron las reflexiones de cada persona respecto al texto, su convivencia y autorreconocimiento, los cuales permiten acercarse a la complejidad de residir en las instituciones totales, como son los centros penitenciarios.

EL ACD, según Fairclough (2008), considera el discurso como el uso lingüístico hablado o escrito (aunque lo audiovisual y la comunicación no verbal también se toma en cuenta), por lo que el discurso será una práctica social-situada histórica, "que es constitutivo de identidades sociales, relaciones sociales y sistemas de conocimiento y creencias" (p. 172), de manera convencional y creativa. El autor propone tres dimensiones-perspectivas para analizar o leer los vínculos entre eventos discursivos particulares: a partir de si el texto es oral o escrito, desde una práctica discursiva, o desde una práctica social. Al analizar las literacidades de las PPL participantes de acuerdo con la práctica discursiva del ACD, nos centramos en los aspectos sociocognitivos de la producción y la interpretación de los textos, el modo en que producen e interpretan estos, así como el interior de las relaciones de poder y dominación en que se está inmerso. A continuación, mostramos las reflexiones sobre la información de las líneas de interpretación en forma general con base en esta perspectiva de análisis.

Tabla 3. Perspectiva general desde el ACD

\begin{tabular}{|c|c|}
\hline Línea de interpretación & Perspectiva del ACD desde la práctica discursiva \\
\hline $\begin{array}{l}\text { Línea uno: entender la reclusión } \\
\text { desde adentro y el reconocimiento } \\
\text { de sí mismos }\end{array}$ & $\begin{array}{l}\text {-Los participantes resaltan que no es posible entender el encierro y } \\
\text { la reclusión si no se está recluido. Por ello, aceptan el vínculo con la } \\
\text { cartografía y sus escritores } \\
\text {-Los participantes se reconocen un colectivo de un taller de escritura }\end{array}$ \\
\hline $\begin{array}{l}\text { Línea dos: textos libres, papel reci- } \\
\text { clado o piñatas: cómo se mueve la } \\
\text { lectura dentro y fuera de una cárcel }\end{array}$ & $\begin{array}{c}\text {-El } 72.7 \% \text { de los participantes aceptaron haber guardado la antología } \\
\text { de lecturas que se les proporcionaba semana a semana. El } 27.3 \% \text { que } \\
\text { no lo hizo aceptó haber tirado, regalado o utilizado el papel como } \\
\text { materia prima para hacer artesanías }\end{array}$ \\
\hline \multirow{4}{*}{$\begin{array}{l}\text { Línea tres: arrastrar el lápiz..., otras } \\
\text { escrituras no literarias: ¿qué escri- } \\
\text { ben las PPL en su vida cotidiana? }\end{array}$} & $\begin{array}{l}\text {-Se dan a conocer las prácticas letradas vernáculas (o autogenera- } \\
\text { das) que se desarrollan en ese contexto privado }\end{array}$ \\
\hline & $\begin{array}{l}\text {-Ofrecen información sobre lo que es entendido por literatura, así } \\
\text { como sus formas de entender y apropiar el término }\end{array}$ \\
\hline & -Se muestra la interacción personal que se vive en ese contexto \\
\hline & -Se muestra la producción de textos de los participantes PPL \\
\hline $\begin{array}{l}\text { Línea cuatro: resonancias, espejos y } \\
\text { puentes con la lectura }\end{array}$ & $\begin{array}{l}\text {-Se destaca la interdiscursividad e intertextualidad que los par- } \\
\text { ticipantes PPL ofrecen poniendo de relieve los textos que fueron } \\
\text { transformadores en su pasado y presente. Textos previos y nuevos } \\
\text { que conformaron resonancias, espejos y puentes con ellos }\end{array}$ \\
\hline $\begin{array}{l}\text { Línea cinco: ¿qué es el encierro y qué } \\
\text { abarca? Reflexiones en torno al tema } \\
\text { de la cartografía }\end{array}$ & $\begin{array}{l}\text {-Los participantes redefinieron su concepto de encierro después de } \\
\text { leer e interpretar las } 13 \text { lecturas de la cartografía lectora }\end{array}$ \\
\hline
\end{tabular}

Domínguez / Sánchez / Ojeda. "Miradas otras”: promoviendo prácticas de lectura y escritura desde una cárcel mexicana Sinéctica 58 www.sinectica.iteso.mx 


\section{Bitácoras como experiencias lectoras}

Es importante visibilizar fragmentos de la recepción de cada una de las 13 lecturas, las cuales se encuentran en el anexo del artículo. Tomamos como muestra un fragmento de cada uno de los participantes, que, a su vez, se eligieron de manera personal, parcial, por la mediadora (es importante señalar que este transvase de datos está sesgado, ya que existen bitácoras muy extensas que rebasan las cinco cuartillas y que más bien parecían ensayos filosóficos completos, cuentos, crónicas, autobiografías). La finalidad es que se lea directamente a los autores con fragmentos transcritos con sus significados textuales, emocionales, biográficos, sociales, políticos, como señala Bustelo (2017), que generan saberes personales y colectivos, apropiaciones de lecturas, de prácticas autorreflexivas escriturales, y de todo aquello que acompaña al contexto histórico sociocultural de un texto.

\section{Discusiones}

Comprobamos la utilidad del método de investigación-acción en este tipo de intervenciones; aun cuando no hubo una interacción presencial, la estrategia implementada permitió conocer las literacidades de los participantes. En la lectura y escritura quedaron plasmadas sus prácticas sociales y culturales, y lograron estimular la autorreflexión (Botella y Ramos, 2019; Federighi, 2019; Kumar, 2018). Con la información que ofrecieron los participantes en sus bitácoras, queda claro que, como lo mencionan Sánchez y Druker (2021), la experiencia lectora en un taller de fomento a la lectura no debe perseguir un único fin ni dirigirse a transmitir una idea si no se acepta como una dimensión de la lectura, la creación de significados textuales, emocionales, biográficos, sociales, políticos. Hay múltiples modos de leer, y cada uno es legítimo, con distintos niveles de importancia para los lectores (Cassany y Castellà, 2010). Como quedó demostrado, se puede despegar una trayectoria de vida propia con las lecturas y crear significados sociales y políticos, pero, en otras ocasiones, el lector se queda en un nivel emocional y no habría que "enjuiciar" que alguien permanezca en esta dimensión de la lectura. Todos son procesos y el promotor debería ser consciente de su acompañamiento en esta disciplina.

Las bitácoras de los participantes muestran la heterogeneidad a la que conduce la lectura y la escritura. Para Cassany y Castellà (2010), la práctica lectora se vincula al entorno social del aprendiz; sin embargo, aunque los participantes PPL acercaron todo lo leído y escrito a su entorno de encierro, la lectura favorita no fue escrita por un PPL o relacionada con un tema carcelario propiamente, aun cuando la mitad de la cartografía estuvo orientada al encierro carcelario. Más que reflexiones sobre los textos, las bitácoras se volvieron en conjunto mapas de significados variados, en los que las lecturas de la cartografía, muchas veces, fueron pretextos para ensayar sobre distintos temas, para crear listas, propuestas, autobiografías, simples flujos de conciencia, pero también para elaborar resúmenes de los textos, reseñas, crítica literaria con investigación documentada, y hacer uso de diferentes elementos como la intertextualidad o interdisciplinariedad con el cine, la música, la filosofía, la teología, la biología, la medicina o el derecho, entre otras.

La creación de una cartografía es un reto para todo promotor de lectura. Son incalculables las opciones y hay que saber delimitar cuando se tiene la urgencia de 
ofrecerlo todo al otro. Descubrimos que es difícil encontrar producción literaria de mujeres en reclusión o textos publicados por editoriales de renombre, en los que sí hay hombres que han tenido más oportunidades en este aspecto, aunque, según las estadísticas del Cuaderno Mensual de Información Estadística Penitenciaria Nacional (2021), el 94.38\% de las personas en reclusión son hombres, y las mujeres en reclusión representan una minoría. No obstante, existen espacios como el programa Documentación y Estudios de Mujeres, que tiene un registro de las narrativas de mujeres en reclusión, que, a pesar de no ser una editorial, sí es una organización civil preocupada por resguardar estas literaturas.

También, hay colectivos autogestionados como la Red Feminista Anticarcelaria de América Latina, la cual, desde sus espacios, difunden su lucha, testimonios, narrativas, reflexiones y demandas de las mujeres que sufren corporalmente la violencia de los estados penales, y distinta producción de talleres en cárceles como el Taller Colectivo de Edición del Programa de Extensión de Cárceles en Argentina, la Colectiva Editorial "Hermanas en la Sombra”, en México, el taller de escritura creativa "Libertad bajo palabra", en Colombia, entre otros.

Un tema de reflexión es la necesidad de continuar con el fomento de la lectura y escritura en las cárceles, ya que estas prácticas son actos de emancipación y hay que repensar a los sujetos desde la complejidad de sus experiencias, lo que supone, entonces, reconfigurar las prácticas de lectura y escritura no con fines técnicos ni reproductivos de un relato cultural hegemónico, sino situándolos en coordenadas emancipatorias y políticas (Sánchez, 2021). De acuerdo con la experiencia de Parchuc (2021), es posible que, a partir de estos esfuerzos, se formen redes que alcancen los niveles institucionales.

De igual forma, es imperante crear una red de bibliotecas penitenciarias en México con una cobertura que alcance a todas las PPL para que puedan acceder a una biblioteca de calidad "con textos pensados para las necesidades y características de cada tipo de recinto penal" (Rivera, 2019, p. 21), y sepan cómo acercarse a estos espacios seguros con la mediación de promotores de lectura que puedan invitarlos a la cercanía del libro y acompañarlos en este camino; a todos, no únicamente a los lectores con estudios universitarios o lectores ávidos, sino buscar acercar a más PPL y elogiar y ennoblecer los beneficios de ser parte de un taller de lectura y escritura penitenciario.

Es urgente democratizar la educación, la lectura y la escritura creativa en todos los espacios $y$, para esto, se requiere seguir construyendo múltiples miradas empíricas de la lectura (Bombini, 2008), en contextos como el de encierro y también como en cualquier otro en el que se trabaje. Estas prácticas no son estáticas ni se crean siguiendo una única metodología; deben renovarse todo el tiempo dependiendo de su función, contexto, grupo de intervención y demás variables específicas del entorno y los participantes con quienes se trabaje.

\section{CONCLUSIONES}

Esta intervención penitenciaria fue una experiencia satisfactoria que cumplió con el objetivo principal de lograr que se compartieran reflexiones críticas, textos, y se estimulara la escritura propia. Fue difícil trabajar de manera no presencial la promoción de la lectura y la escritura en un ambiente penitenciario, porque allí tiene un peso esencial la presencia del externo, del que acompaña en la moderación de 
una actividad como esta. No obstante, la intervención se hizo posible gracias al envío de clases grabadas y videos informativos, lo cual hizo que los participantes se sintieran un poco más acompañados e interesados. Esto se hizo evidente por los agradecimientos que enviaron mediante cartas personales que se mantuvieron todo el tiempo entre la mediadora y los participantes.

A su vez, es necesario seguir estudiando el tema penitenciario desde sus narrativas en México; es posible ser creadores de nuevas referencias teóricas y prácticas, ya que hay poca bibliografía sobre la lectura en espacios penitenciarios; poca literatura propia de PPL publicada y legitimada por otros espacios o instituciones a lo largo y ancho del país; y, evidentemente, poco recurso económico que llegue a la cárcel destinado al tema y a la incentivación de estas prácticas. Esta intervención cuenta con bibliografía de expertos del tema argentinos, más que mexicanos, lo cual es importante decir porque revela que ese país es un pionero y que es bueno conocerlos para poder replicarlos desde otros contextos y proponer nuevos enfoques o métodos. Lo principal es entender que debe generarse un conocimiento propio desde la realidad carcelaria mexicana, aunque se tengan ejemplos de países de todo el mundo.

Por último, se recalca la importancia de publicar más narrativas en contextos de encierro y acercarla a la población que permanece extramuros, presentarles desde diferentes perspectivas, miradas, voces y experiencias de esta realidad. Sin olvidar, como dice Cosgrove (2020), que los archivos se han convertido en los intermediarios del pasado y del presente, que dan a conocer los sujetos por quienes hay que hacer justicia. En ellos se resguarda la memoria y pruebas de las injusticias vividas que servirán como evidencia empírica para próximas condenas, y para el futuro de todos como habitantes del mundo. Hay que recordar que también se suscitan cientos de injusticias dentro de las cárceles mexicanas que no se cuentan ni salen nunca a la luz. Narrativas que pudieran ofrecer una resignificación de la condición de ser PPL y, al mismo tiempo, sea una motivación y espacio abierto de expresión para las mismas personas en reclusión.

Hay que abrir puertas a estas voces, invitarnos a escucharlos, a dejar de desoír lo que ellos tienen para ofrecer, y replicar lo leído, hacer pasar de voz en voz y de mano en mano estas literaturas "Otras" siempre marginalizadas (en los extremos oscuros sociales) contrarias a lo leído, lo aceptado, lo premiado, lo no-incómodo. Literaturas "Otras" que atraviesan rejas, murallas, filtros de seguridad, y también cruzan puentes dolorosos propios hasta llegar finalmente a nosotros, los lectores.

\section{REFERENCIAS BIBLIOGRÁFICAS}

Acin, A. (2016). Aportes interdisciplinarios y pedagógicos a la educación de personas privadas de libertad desde la experiencia en el Programa Universitario en la Cárcel. En B. Bixio y P. Mercado (eds.). Sentidos políticos de la universidad en la cárcel. Fragmentos teóricos y experiencias (pp. 115-143). Argentina: Universidad Nacional de Córdoba. https://ansenuza.unc.edu.ar/comunidades/ handle/11086.1/1122

Aldrete, S. (2000). Me dicen la Narcosatánica. Debosillo, Penguin Random House.

Alexiévich, S. (2015). La guerra no tiene rostro de mujer. Barcelona, España: Debate. 
Argüelles, J. (2020). Escribir y leer en la universidad. Revista de la Educación Superior, vol. 49, pp. 131-134. http://resu.anuies.mx/ojs/index.php/resu/ article/view/1255

Armijo, D. (2018). Flores en la herida. Relatos de personas encarceladas. México: Secretaría de la Cultura.

Auster, P. (2002). Creía que mi padre era Dios. Barcelona, España: Anagrama.

Baricco, A. (2005). Homero, Ilíada. Barcelona, España: Anagrama.

Bombini, G. (2008). La lectura como política educativa. Revista Iberoamericana de Educación, núm. 46, pp. 19-35. https://rieoei.org/historico/documentos/ rie46a01.pdf

Bourdieu, P. (1997). Capital cultural, escuela y espacio social. México: Siglo Veintiuno.

Botella Nicolás, A. M. y Ramos Ramos, P. (2019). Investigación-acción y aprendizaje basado en proyectos. Una revisión bibliográfica. Perfiles Educativos, vol. 41, núm. 163, pp. 127-141. http://perfileseducativos.unam.mx/iisue_pe/index.php/perfiles/article/view/58923

Bustelo, C. (2017). Experiencias de formación en contextos de encierro: un abordaje pedagógico desde la perspectiva narrativa y (auto) biográfica. Trabajo recepcional de Doctorado en Facultad de Filosofía y Letras, Universidad de Buenos Aires. http://repositorio.filo.uba.ar/handle/filodigital/4363

Cassany, D. y Castellà, J. M. (2010). Aproximación a la literacidad crítica. Perspectiva Florianópolis, vol. 28, núm. 2, pp. 353-374. https://doi.org/10.5007/2175795X.2010v28n2p353

Chávez, C. (2020). Inaugura Fundación Plan B, Video Academia Penitenciaria. El pulso de Colima. https://elpulsodecolima.com/2020/08/12/inaugurafundacion-plan-b-video-academia-penitenciaria/

Comisión Nacional de los Derechos Humanos (2010). III. Grupos en situación de vulnerabilidad y otros temas. México. http://informe.cndh.org.mx/menu. aspx?id=23

Cosgrove, K. (2020). El rol del archivo: la memoria resguardada. En M. Mardones Leiva y T. de Armas Pedraza (comps.). El libro y la lectura en recintos penitenciarios (pp. 83-87). Santiago de Chile: Gráfica Nacional. https://bibliotecadigital.mineduc.cl/handle/20.500.12365/17262

Cuaderno Mensual de Información Estadística Penitenciaria Nacional (2021). CE_2021_02, febrero. https://www.gob.mx/cms/uploads/attachment/ file/626744/CE_2021_02.pdf

Dalton, R. (2019). Taberna y otros lugares. México: Fondo de Cultura Económica.

Díaz Pontones, M. y Mora Gutiérrez, L. A. (2018). La educación superior en contextos carcelarios, el caso de la Ciudad de México. Revista Electrónica Cooperación Universidad Sociedad, vol. 3, núm. 1, pp. 14-20. https://doi. org/10.33936/recus.v3i1.1278

Documentación y Estudios de Mujeres, AC (2020). Quiénes somos. https://demac.org.mx/quienes-somos/

Estrada, J. (2016). Literatura entre barrotes. Revista de la Universidad de México UNAM, núm. 147, pp. 32-37. https://www.revistadelauniversidad. $\mathrm{mx} /$ articles/6b0d5b44-32ac-4e2c-88dc-ce9bfb08aa5a/literatura-entrebarrotes 
Estrada, J. (2014). Femfatales. Endebate, Penguin Random House.

Fairclough, N. (2008). El análisis crítico del discurso y la mercantilización del discurso público: las universidades. Revista Discurso y Sociedad, vol. 2, núm. 1, pp. 170-185. http://www.dissoc.org/ediciones/v02n01/DS2(1)Fairclough. html

Federighi, P. (2019). Research methodology in adult learning and education. Journal of Educational Sciences, vol. 20, núm. 39, pp. 58-73. http://dx.doi. org/10.35923/JES.2019.1.05

Frank, A. (2001). El diario de Ana Frank. Barcelona, España: Planeta.

Frías, L. (2019). Diez años de la UNAM en el Centro Femenil de Readaptación Social de Santa Martha Acatitla. Gaceta UNAM Ilustrada, núm. 5020, pp. 12-13. https://www.gaceta.unam.mx/index/wp-content/ uploads/2019/01/170119.pdf

Frugoni, S. (2020). Prácticas literarias en contextos de encierro. Revista Textos. Didáctica de la Lengua y de la Literatura, núm. 90, pp. 36-40. https://dialnet. unirioja.es/ejemplar/559093

Frugoni, S. (2018). Bibliotecas Itinerantes, lecturas y mediadores en contextos de encierro. Revista Catalejos, vol. 4, núm. 7, pp. 114-126. http://fh.mdp.edu. ar/revistas/index.php/catalejos/article/view/2754

Goffman, E. (2001). Sobre las características de las instituciones totales. En Internados. Ensayos sobre la situación actual de los enfermos mentales (pp. 15132). Buenos Aires, Argentina: Amorrortu Editores.

Gómez, M. (2017). Los derechos humanos en las cárceles y centros de reclusión penitenciaria de México. En S. García Ramírez y O. Islas de González Mariscal (comps.). Evolución del sistema penal en México. Tres cuartos de siglo (pp. 7797). México: Instituto Nacional de Ciencias Penales.

Gómez Reyes, J. A. (2019). Los derechos humanos de las personas privadas de la libertad: importancia y aplicación. Revista Mexicana de Medicina Forense, vol. 4, núm. 2, pp. 57-74. https://revmedforense.uv.mx/index.php/RevINMEFO/ article/view/2671

Gramsci, A. (2019). El árbol de los erizos. Barcelona, España: Icaria Editorial.

Gutiérrez de Lucio, A. S., Hidalgo, H. \& Espinosa, N. (2018). Is teaching inside the youth Mexican prison system inclusive? International Congress on the Didactics of the English Language Journal, vol. 3, núm. 1, pp. 1-14. http://revistas. pucese.edu.ec/ICDEL/index

Hernández, M. (1990). Las nanas de la cebolla. Ciudad de México: Ediciones del Naranjo.

Instituto Nacional de Estadística y Geografía (INEGI) (2020). Censo Nacional de Gobierno, Seguridad Pública y Sistema Penitenciario Estatales 2020. https://www.inegi.org.mx/contenidos/programas/cngspspe/2020/doc/ cngspspe_2020_resultados.pdf

Kumar Mohajan, H. (2018). Qualitative research methodology in social sciences and related subjects. Journal of Economic Development, Environment and People, núm. 1, pp. 23-48. http://dx.doi.org/10.26458/jedep.v7i1.571

Maistré de, X. (2020). Viaje alrededor de mi alcoba. Veracruz, México: Instituto Veracruzano de la Cultura.

Martínez, O. (2016). Los migrantes que no importan. Sur Ediciones. 
Morales Reyes, M. M. (2017). El Programa de Educación Superior en los Centros de Readaptación Social (PESCER) en la Ciudad de México. Una evaluación de la gestión desde el enfoque de las políticas públicas. Tesina de licenciatura en Administración Educativa, Universidad Pedagógica Nacional. Repositorio Institucional. http://200.23.113.51/pdf/34169.pdf

Morales Sánchez, M. I. (2019). La lógica de la lectura: de la lectura estética o "el arte de leer con sentido". En E. M. Ramírez Leyva (coord.). De la lectura académica a la lectura estética (pp. 59-77). México: Instituto de Investigaciones Bibliotecológicas y de la Información, UNAM. http://ru.iibi.unam.mx/jspui/ handle/IIBI_UNAM/L217

Morondo Taramundi, D. (2020). Vulnerabilidad y derechos humanos. Revista Tiempos de Paz, núm. 138, pp. 20-27. http://revistatiempodepaz.org/revista138/\#dflip-df_1654/22/

Mutis, A. (1960). Diario de Lecumberri. Xalapa, Veracruz: Universidad Veracruzana.

Orozco López, M. T. y Pérez Amezcua, L. A. (2021). El triángulo "L” en México: lectura, literatura y literacidad. Sinéctica. Revista Electrónica de Educación, núm. 56, pp. 1-18. https://sinectica.iteso.mx/index.php/SINECTICA/article/ view/1176/1390

Ortiz Cirilo, A. (2014). La educación en las prisiones de México. Antecedentes históricos y la formación en valores en la propuesta del MEVyT penitenciario. Tesina de licenciatura en Pedagogía, Universidad Pedagógica Nacional. Repositorio Institucional Universidad Pedagógica Nacional. http://200.23.113.51/ pdf/30365.pdf

Parchuc, J. (2021). Un hilito de luz: usos de la literatura y otras formas de arte y organización en la cárcel. Educação Unisinos, núm. 25. http://revistas.unisinos.br/index.php/educacao/article/view/21022/60748518

Parchuc, J. (2020). Escribir en la cárcel. Prácticas y experiencias de lectura y escritura en contextos de encierro. Argentina: Facultad de Filosofía y Letras, Universidad de Buenos Aires.

Parchuc, J. (2014). Escribir en la cárcel: acciones, marcos, políticas. Boletín de la Biblioteca del Congreso de la Nación, vol. 128, pp. 67-81. https://ri.conicet. gov.ar/handle/11336/42669

Pasos, J. (1978). Canto de guerra de las cosas y otros poemas. México: Universidad Nacional Autónoma de México.

Reinserta, A.C. (2020, octubre). Diagnóstico sobre la percepción del desempeño de la defensoría penal en México. https://reinserta.org/

Revueltas, J. (1979). El apando. México: Porrúa.

Rivera Donoso, M. (2019). Las bibliotecas en cárceles y la vinculación con el medio. En M. Mardones Leiva y T. de Armas Pedraza (comps.). El libro y la lectura en recintos penitenciarios (pp. 17-25). Santiago de Chile: Gráfica Nacional.

Sánchez Lara, R. A. (2021). Prácticas de lectura y escritura: la importancia de repensar al sujeto complejo para la justicia educativa. Contextos: Estudios de Humanidades y Ciencias Sociales, núm. 48, pp. 1-16. http://revistas.umce.cl/ index.php/contextos/article/view/1593

Sánchez Lara, R. A. y Druker Ibáñez, S. D. (2021). Educación literaria: reconocimiento complejo y participación legítima del lector literario como actos de justicia educativa. Revista Álabe, núm. 23, pp. 1-18. http://revistaalabe.com/ index/alabe/article/view/585 
Sequeiros, P. (2018). Holding the dream': Women's favorite readings in a Portuguese prison. Qualitative Sociology, vol. 14, no. 1, pp. 110-128. https://doi. org/10.18778/1733-8077.14.1.06

Temple, G. (2018). The ambivalent pleasure of teaching early American literature in a prison. The Journal of Nineteenth-Century Americanists, vol. 6, núm. 2, pp. 219-228. https://doi.org/10.1353/jnc.2018.0018

Vilchez, M. (2020). La cárcel es el lugar de lo imprevisible. Entrevista a Sergio Frugoni. Revista Catalejos, vol. 10, núm. 5, pp. 181-197. https://fh.mdp.edu. ar/revistas/index.php/catalejos/article/view/3629

Villalobos, J. P. (2010). Fiesta en la madriguera. Barcelona, España: Anagrama.

Zavala, V. (2008). La literacidad o lo que la gente hace con la lectura y la escritura. Textos de Didáctica de la Lengua y la Literatura, núm. 47, pp. 71-79. https://www.grao.com/es/producto/la-literacidad-o-lo-que-la-gente-hacecon-la-lectura-y-la-escritura

Anexo. Bitácoras como experiencias lectoras

\begin{tabular}{|c|c|}
\hline Participante & Reflexiones sobre la lectura \\
\hline A.B. & $\begin{array}{l}\text { En bitácora Los migrantes que no importan (febrero, 2021): “La suprema corte en vez de } \\
\text { andar inventando más delitos pendej... como la restricción de dulces, la chancla, los piropos, } \\
\text { etc., y las sentencias como para dinosaurios. Que invente una ley como la de Canadá para } \\
\text { trabajar por determinados tiempos -todo aquel que migre o pida asilo 'bienvenido' siem- } \\
\text { pre y cuando trabaje por la derecha- pero ya si empieza a acer [sic] chingaderas o tratar de } \\
\text { implementar sus ideas chafas que porque así es allá de donde vienen, que ni se quejen si les } \\
\text { empieza a ir mal. Yo algunas veces viajé sin dinero ni papeles a ciertos lugares solo por el } \\
\text { gusto de conocer aplicando } 5 \text { ideas básicas: todo viajero o migrante, trabajador honrrado [sic] } \\
\text { callado respetuoso y agradecido....donde quiera es bienvenido" }\end{array}$ \\
\hline C.A. & $\begin{array}{c}\text { En bitácora Diario de Lecumberri (marzo, 2021): “Nadie, nunca, en ningún lugar; se acostum- } \\
\text { brará a estar en prisión. [...] La droga es un paliativo para la 'enfermedad del cautiverio', lo- } \\
\text { cura temporal y crónica, adquirida con el tiempo. [...] Aquí es una realidad despertar con 'un } \\
\text { espeso sabor a trapo que nos seca la boca y nos impide dar los buenos días'. [...] No pretendo } \\
\text { sonar como un ser egoísta, pero ¿Por qué la historia de alguien más podría resultar más con- } \\
\text { movedora, que incluso mi propia historia?” }\end{array}$ \\
\hline E.G. & $\begin{array}{l}\text { En bitácora El apando (febrero, 2021): “Me causa conflicto porque Revueltas refleja, muestra } \\
\text { y exhibe la miseria personal dentro de la miseria humana. [...] El Carajo es Naca 'el Pasito } \\
\text { Perrón' de Pacho (en nuestra versión actual) personas fantasmas, presentes en todos lados, } \\
\text { dueños de este submundo, muy necesarios en el engranaje de este sistema perverso, inexis- } \\
\text { tentes para la sociedad, que deambulan por los rincones con rejas haciendo suya la cárcel, a } \\
\text { su manera, fantasmas sobreviviendo, buscando entre la basura lo que para unos ya no sirve, } \\
\text { y que para ellos es una moneda, verdaderos maestros del reciclaje. [...] Lecumberri, Pacho, } \\
\text { la cárcel es lugar de sufrimientos exponenciales, de hipocresías y mentiras desmedidas, } \\
\text { desmesuradas, y por lo tanto, comunes. [...] Es también palacio, la cárcel, de sexo y lujuria } \\
\text { desbordados, donde cohabitan las manías y perversiones clandestinamente a sus anchas. [...] } \\
\text { Lecumberri se expandió y mutó y sus tentáculos nos alcanzan a todos” }\end{array}$ \\
\hline F.del C. & $\begin{array}{l}\text { En bitácora El permiso (enero, 2021): “El permiso, es como abrir una gran llave: dejar salir el } \\
\text { torrente, cae de golpe todo... los años, los tantos años es ver que no está lo que dejaste, que } \\
\text { nada está en pausa, todo sigue su curso... los que fueron adolescentes hoy son padres, los } \\
\text { padres abuelos, los espacios vacíos se llenaron. [...] Creo que desde donde escribo entiendo } \\
\text { mucho de lo que describe... la llamada para la fatalidad... El recodar los detalles de los buenos } \\
\text { tiempos... Sentir tu celda fría, un espacio que no te pertenece, compartirlo, tolerar a intolera- } \\
\text { bles (jaja se oyó raro) pero es así todos somos parte de todo y de nada a la vez” } \\
\text { En bitácora El diario de Ana Frank (noviembre, 2020): “El diario de Ana Frank... bien podría } \\
\text { llamarse Radiografía Intramuros. [...] Es algo como a veces me pasa... vivo encierro en el } \\
\text { encierro, mini guerras, juego de poderes, cambio de roles y estamos a merced del ánimo de } \\
\text { otros” }\end{array}$ \\
\hline
\end{tabular}

Domínguez / Sánchez / Ojeda. "Miradas otras”: promoviendo prácticas de lectura y escritura desde una cárcel mexicana Sinéctica 58 www.sinectica.iteso.mx 


\begin{tabular}{|c|c|}
\hline C.E. & $\begin{array}{l}\text { En bitácora La guerra no tiene rostro de mujer (noviembre, 2020): "La guerra no tiene cara de } \\
\text { mujer ni de hombre más bien tiene cara de un mundo deshumanizado. [...] Porque la guerra } \\
\text { está en todos lados, en nuestra cultura, historia y religión. Por qué le pedimos a un Dios, a } \\
\text { qué Dios, al Dios de los ejércitos, porque Dios necesita un ejército siendo un Dios. Los dioses } \\
\text { pueden jugar a la guerra, pero solo es un juego porque no se dañan, porque son inmortales. } \\
\text { Pero nosotros somos mortales, sensibles, somos humanos" } \\
\text { "En el mundo hay un juego representado en un tablero, sesenta y cuatro cuadros, dos matices, } \\
\text { dos reinos, por qué sacrificar lo que tienes, porque tienen que morir; sacrificas un peón por } \\
\text { salvar un caballo o un caballo para matar un alfil, incluso a tu reina para salvar al rey, para } \\
\text { que viva el rey por qué no sacrificar al rey si se supone que el rey ama a su reina, o sacrificas } \\
\text { una torre que es parte de tu patrimonio de tu reino y cuál es la ganancia: muerte, dolor, ham- } \\
\text { bre, soledad y te dices victorioso y todo eso, ¿Para qué?, para comenzar otra guerra" }\end{array}$ \\
\hline F.G. & $\begin{array}{l}\text { En bitácora Diario de Lecumberri (marzo, 2021): “Es claro que cumple la función de brindar } \\
\text { un espejismo, una falsa libertad, tan efectiva que cuando no mantiene en placenteros sue- } \\
\text { ños al reo, lo somete en frenética búsqueda del recurso para obtener más. [...] Más cárcel } \\
\text { dentro de la cárcel. [...] No me parece una figura estereotipada, al contrario fidedigna. } \\
\text { [...] Lo que me desagrada es la poca o nula búsqueda de la libertad verdadera. [...] 'En la } \\
\text { cárcel cada cual tiene sobre sí un peso tal de angustia y desesperanza, que el dólor de los } \\
\text { otros resbala como el agua sobre las plumas de los patos' (iqué tal eres! Perdón, eso fue } \\
\text { totalmente canero ja,ja,ja. [...] Propongo maestra, por otra parte, lecturas que incentiven } \\
\text { la búsqueda por la libertad con justicia, porque estará de acuerdo que si bien es cierto que } \\
\text { ya hablamos del encierro y la paz, no puede haber paz con encierros sin justicia y, el único } \\
\text { camino a esta es por medio del derecho” } \\
\text { En bitácora Epílogo: Otra belleza: apostilla sobre la guerra (marzo, 2021): “Como persona en } \\
\text { cautiverio (estado de la persona que aprisionada en la guerra, vive en poder del enemigo. } \\
\text { Gran Diccionario Patria de la Lengua Española, Bilbao: Durván, México: Patria, 1994, Alfagua- } \\
\text { ra), en mi opinión la principal guerra que se libra, es contra el tiempo, tan es así que una de } \\
\text { las máximas del derecho reza: 'Justicia tardía, no es justicia”” }\end{array}$ \\
\hline J.P. & $\begin{array}{l}\text { En bitácora Diario de Lecumberri (marzo, 2021): “Desde el arranque de su diario Mutis conec- } \\
\text { ta con situaciones y sensaciones que son claves en la vivencia de la cárcel. [....] Me impre- } \\
\text { sionan las múltiples conexiones que encuentro entre la vida en el Palacio Negro de Lecum- } \\
\text { berri (Revueltas, Mutis) y mi vida en el penal de Pacho, a sesenta años de distancia. [...] La } \\
\text { experiencia colectiva de los traslados, durante la madrugada de hace tan solo unos días (ahí } \\
\text { en Pacho), instaló en esta colectividad carcelaria que hacemos, la presencia del miedo que } \\
\text { describe Mutis claramente cuando en el Lecumberri de hace sesenta y un años comienzan a } \\
\text { morir azarosamente los adictos a la tecata que inyectan en sus súper-carreteras-sanguíneas, } \\
\text { la fulminante 'tecata balín'. [...] Así, el 'Diario' es un relato pleno de resonancias, por supuesto, } \\
\text { para quienes vivimos y resistimos en la cárcel, pero a su vez es un trabajo generador de puen- } \\
\text { tes hacia todas las personas que resistimos creativamente a la enajenación, a los confinamien- } \\
\text { tos, a las diversas formas de violencia en el mundo hoy existentes, a la apatía y la rutina que } \\
\text { carcomen el espíritu crítico, solidario y libertario que nos vincula socialmente y nos afirma en } \\
\text { la cotidiana batalla de construir 'un mundo donde quepan muchos mundos' incluyente de los } \\
\text { subalternos, integrados por las múltiples diversidades que enriquecen y fortalecen al tejido } \\
\text { humano que somos" }\end{array}$ \\
\hline L.H. & $\begin{array}{l}\text { En bitácora Femfatales (febrero, 2021): “No pos' ora si sentí que nos brincamos la barda con } \\
\text { esta lectura, no por los temas que trata (sexo, robo, prostitución) sino porque me sentí fuera } \\
\text { del contexto carcelario, me ha gustado que se hayan dejado las entrevistas con las palabras } \\
\text { que fueron relatadas. [...] No solo fueron los temas expuestos de las lecturas, sino la naturali- } \\
\text { dad con que fueron escritos lo que aún me sigue atrayendo" }\end{array}$ \\
\hline J.L. & $\begin{array}{c}\text { En bitácora El árbol de los erizos (diciembre, 2020): “Lo primero: me golpeó la primera } \\
\text { carta, por el título 'Aventura Navideña' ya que aquí voy por mí también segunda navidad. [...] } \\
\text { Tengo noción de la historia de Gramsci ya que cuando estuve en Italia, específicamente en } \\
\text { Vizenza se le conoce allí como una persona que abogó por que el hombre y la mujer pudieran } \\
\text { construir cosas mutuamente. [...] Mis padres fueron refugiados de la guerra civil en México, } \\
\text { y siento que a pesar de su ideología, con nosotros que somos } 3 \text { hermanos, no fueron tan } \\
\text { intransigentes" }\end{array}$ \\
\hline
\end{tabular}




\begin{tabular}{|c|c|}
\hline J.M. & $\begin{array}{l}\text { En bitácora Diario de Lecumberri (marzo, 2021): “En la vida hay pocas probabilidades de caer } \\
\text { en la cárcel, pero si esto sucede, hay muchísimas probabilidades de caer por segunda vez y } \\
\text { así sucesivamente [...] invariablemente se llega a la cárcel, es como un lastre del cual es arduo } \\
\text { escapar, o librarse de esta invisible carga multifactorial que propicia el acceder a la máxima } \\
\text { casa de estudios de la vida, llamada prisión. [...] Más de } 25 \text { compañeros he visto partir de este } \\
\text { sitio en calidad de cadáveres, y a más de una decena asistirlos durante la agonía o minutos } \\
\text { después de caer inertes por enfermedades, suicidios, o causas externas por terceros. Todos } \\
\text { invariablemente sufrimos un adiestramiento donde poco a poco vamos endureciendo la } \\
\text { coraza que nos permite afrontar las continuas pérdidas y amputaciones sociales, económicas, } \\
\text { emocionales que produce el exilio en estos lugares, esto no produce inmunidad, los golpes se } \\
\text { resisten, las lágrimas se quedan a punto de brotar, los nervios crispados, las noches insomnes, } \\
\text { los bolsillos vacíos, la soledad poco a poco va carcomiendo la existencia” }\end{array}$ \\
\hline Y.G. & $\begin{array}{c}\text { En bitácora "El permiso" (enero, 2021): “La cárcel te desgasta, te va consumiendo. [...] No sé } \\
\text { qué hizo, ni cuándo saldrá, pero su relato no contiene ninguna esperanza de volver a reunirse } \\
\text { con ellos. [...] Aquí me han contado muchas historias donde el común denominador es que la } \\
\text { familia te olvida, te abandona, no recibes afecto del exterior. Por ello aquí forman una nueva } \\
\text { familia, a sus compañeras les dicen 'abuela' o 'mamá' o 'hermana', se consiguen una pareja, y } \\
\text { así al inventarte una nueva vida aquí deja de doler o duele menos lo que perdiste que está allá } \\
\text { afuera” } \\
\text { En bitácora Femfatales (febrero, 2021): “En el Cereso hay muchas mujeres con historias muy } \\
\text { fuertes y muchas de ellas adoran a la Santa Muerte, la tienen tatuada, la llevan en una cadena, } \\
\text { le ponen veladoras, cigarros, alcohol no porque no lo dejan pasar, comida. La cuidan y están } \\
\text { siempre al pendiente de ella” }\end{array}$ \\
\hline
\end{tabular}

